\title{
Transition Related Dilemmas of Persons with Developmental Disabilities
}

\author{
Ma. Concepcion C. CABATAN, MHPEd, OTRP, OTR ${ }^{1}$ \\ ${ }^{1}$ Department of Occupational Therapy, College of Allied Medical Professions, \\ University of the Philippines Manila
}

\begin{abstract}
This study describes school to post-school transition problems, factors, activities and professionals involved in transition. Parents $(n=86)$ of children with developmental disabilities, aged 14 and older, answered a questionnaire addressing study objectives. Parents reported work, psychological, coping and environmental problems related to transition. Factors perceived to facilitate smooth transition include coordination among service providers, early planning, presence of support systems and training in and exposure to post-school environments/activities. Lack of adolescent and adult programs, absence of planning and lack of knowledge about transition were perceived to hinder smooth transition. Activities listed for transitioning include planning, contact with agencies, professionals and potential employers, and work training. Teachers, doctors and occupational therapists were reported to be involved in the process. Results suggest a practice area addressing adolescent and adult needs. Further studies are needed to explore the efficacy of transition programs for this population.
\end{abstract}

Key words: school to work transition, developmental disabilities, transition planning and activities

(Asian J Occup Ther 3: 15-26, 2004)

\section{Introduction}

Developmental disability (DD) represents a chronic, mild or severe group of disabilities resulting from mental or physical impairment or a combination of both. It also results in a substantial

Received: September 1, 2003, Accepted: February 25, 2004 Corresponding to: Ma. Concepcion C. Cabatan; Department of Occupational Therapy, College of Allied Medical Professions, University of the Philippines Manila, P. Faura St. Ermita, Manila, Philippines phone: 632-524-5113/632-716-0124 fax: 632-526-2271 e-mail:Cabatan@edsamail.com.ph mccab@mail.upm.edu.ph functional limitation in three or more key areas of living (McDonnell, Wilcox \& Hardman, 1991; Siporin, 1999). These areas include self-care, receptive and expressive language, learning, mobility, self-direction, capacity for independent learning, and economic sufficiency. Another working definition of DD conceptualized by Shapiro (as cited in Reyes, 1990) characterizes it as any disorder that critically affects a person's quality of life. This spectrum of disabilities include diagnoses such as mental retardation, autism, cerebral palsy, deaf-blind, learning disabilities, attention deficit disorder, and communication disorders (Clark \& Kolstoe, 1995; 
McDonnell et al., 1991; Shapiro as cited in Reyes, 1990).

As major areas of living are affected, persons with DD require ongoing support from their families, health, education, and social services throughout their lifespan (Siporin 1999; McDonnell et al., 1991). Required services range from early intervention, special education, and vocational services that are modified as they grow older and their needs change. In the Philippines, most of the services are focused on early intervention and special education programs. Johnson (1995) asserted that there is a dearth of post-school programs for adolescents and adults with disabilities.

When it is time for persons with DD to leave the school environment, their families are in quandary as to what they will do. Some families expect them to be ready for work training, work per se or to function optimally in the community following completion of a school program. Options in the Philippines for this age group are limited and inadequate. When it is time for families to search for post-school placements, they discover that their children are inadequately prepared in terms of work skills and environment. Because of insufficient training, employment is difficult to find. Others resort to placing them back to school programs for further training or to simply keep them occupied. Many were also reported to stay home. As such, idleness and sometimes regression to infantile behaviors were also reportedly observed.

These experiences have heightened awareness among parents and professionals to address the need to prepare adolescents/adults with developmental disabilities for post-school environments. This preparation period is referred to as transition in this paper. This study documented transition related dilemmas and examined the factors that affect transition to a post-school environment. The investigator also identified activities and professionals involved in transition. It hoped to contribute to a knowledge base of the status of transition and adult programs for persons with developmental disabilities, and the extent of need for additional support services required in a developing country such as the
Philippines. This project aimed to provide impetus to create and develop transition programs by adult service providers and educational institutions. With transition programs in place for persons with disabilities, post-school adjustment and placement problems can be anticipated and minimized. This study can also be used to justify the design of individualized transition plans for adolescents with special needs.

Using a survey questionnaire, this study attempted to answer the following questions:

1. What problems are commonly observed among those with transition and without transition?

2. What factors facilitate/hinder smooth transition to post school environments?

3. What activities are used to transition persons with developmental disabilities from school to post-school environments?

4. Who are the professionals involved in the transition process?

The words "problem" and "dilemma" are used interchangeably throughout the paper. They refer to obstacles experienced and observed when a person with DD is prepared for post-school environments. Problem categories were operationally defined as:

1. Psychological-emotional responses to a variety of situations such as confusion, depression, withdrawal, and anxiety.

2. Coping - difficulties in adjusting or modifying behavior in response to environmental demands such as accommodating change, learning new routines, and interacting with new persons.

3. Behavioral-engagement in nonproductive or maladaptive responses such as helplessness, increase in selfstimulatory activities, and preference for inactivity.

4. Work-related-difficulties related to carrying our tasks or responsibilities in school or non-school environments such as irregular attendance, learning work skills, managing money, and frequent tardiness.

5. Environmental - constraints or limitations found within context of family, community, and society such as lack of 
support, lack of job options, lack of leisure opportunities, and no income to live independently.

\section{Literature Review}

\section{Transition Events}

Social scientists have theorized that in a person's lifespan, transitions are inevitable. Going to school, getting a job, moving to new place, and getting married are typical examples of transition events. Because it is a change that brings about “temporary disequilibrium" in a person's life, stress is experienced (Blair, 2000, p. 232). One of Levinson's stages of adulthood focused on the transitional period from adolescence to early adulthood (Rice, 1995). This period is characterized by stable and transition episodes. According to Levinson, it is during stable periods that adults develop values, belief systems, and life priorities. It is during times of transition that these may be modified in response to events. These episodes are closely related to Havighurst's developmental tasks of young adults, which include finding a job, spouse, and living away from parents (Rice, 1995; Schulz \& Ewen, 1993). For the average person, transitions may be easily negotiated. A modification in routine, habit, and activity patterns is a typical response.

For persons with DD, one change is their transition from school to post-school environments that usually occurs between the ages of 14 to 22. A post-school environment may be a work place, new residence, an adult education program or living in the community. This is a period of preparation to enter these adult environments (Chandler, O'Brien, \& Weinstein, 1996; Clark \& Kolstoe, 1995; Horne \& Morris, 1998; McDonnell et al., 1991). They need to learn new response sets to deal with role change, new routines, responsibilities, occupations, skills, and habits. (Hanley-Maxwell, Whitney-Thomas, \& Pogoloff, 1995; Jacobs, Mazonson, Pepicelli, Clague, \& Leekoff, 1985).

A study by Hanley-Maxwell, WhitneyThomas et al. (1995) described the visions of parents of children with disabilities. They portrayed their children working, living independently, and having a network of friends outside of the family unit. Schuster, Graham and Moloney (2000) conducted a survey on post-high school expectations of students with disabilities and their parents. Students had higher expectations for themselves than their parents. They expected to work after high school congruent with their perception that it is a means to earn money, meet people, and feel responsible. Another study by Whitney-Thomas and HanleyMaxwell (1996) revealed that parents experience a "greater discomfort and pessimism" of the future of their children with disabilities (p. 75). The time to confront a permanent departure from a school environment elicits tension and ambivalence (Blair, 2000) that affect family members.

The adjustment from school to a post school environment can be a difficult process.

It is well documented that a large number of persons with DD are unemployed or underemployed, have no or little access to leisure and community activities, are unable to make life decisions, and have very little independence (Clark \& Kolstoe, 1995; McDonnell et al., 1991). Many are not given opportunities to select their preferred placements. For those who work, Siporin (1999) reported that there was very little, if any, social interaction occurring between workers with DD and those without. She postulated that deficient preparation for a work environment was a reason for the lack of social interaction. Similarly, McInerney and McInerney (1994) found that adolescents with disabilities are deficient in social skills and work behaviors. A lack of essential skills for daily life in the community makes adolescents and adults with disabilities susceptible to maladjustment.

Hanley-Maxwell, Whitney-Thomas et al. (1995) asserted that the needs of this population require reliable and accessible services, wider range of residential options, support networks, and diverse experiences for successful transition.

\section{Transition programs}

In the United States, federal regulations such as the Individuals with Disabilities Education Act (IDEA) and the School-to-Work Opportunities Act (STWOA) provided for transition services to 
promote movement from school to post-school environments. Services included the following: post-secondary education, vocational training, integrated employment, adult services, independent living, and community participation (Clark \& Kolstoe, 1995; Horne \& Morris, 1998). In the Philippines, Republic Act 7277, also known as Magna Carta for Disabled Persons, does not have an explicit provision for transition services or programs.

Literature provided a variety of programs that address transition. Davidson and Fitzgerald (2001) described a client-centered transitionplanning scheme aimed to facilitate a student's successful movement and integration from school to community environments. O'Reilly (2000) described a Transition Individual-Education Program of the Rochester Regional Transition Coordination Site. Getzel and Kregel (1996) proposed an employment connection program. McInerney and McInerney (1994) introduced a proactive occupational therapy program that addressed transition needs. Occupation-based programs (Ethridge, Dimmer, Harrison, \& Davis, 1989; Giese, 2000; Kluver, Clark, \& Hoffman, 1998 ) conducted in the community provided persons with DD opportunities to practice skills in natural settings. Schlien and Ray (1997) proposed the inclusion of therapeutic recreation services for a comprehensive transition program.

Occupational therapists are significant players in transition programs especially in the training of community living skills. Davidson and Fitzgerald (2001), Giese (2000), and Kluver et al. (1998) affirmed that our background on occupational performance provided occupational therapists the requisite to create community based instruction in instrumental activities of daily living (IADL), work task adaptations, communication, self-advocacy, consumer and legal issues, health management, housing options, personal assistance management, recreation, and transportation.

In the four programs described above and in other literature (Schuster, Graham, \& Moloney, 2000), coordination and collaboration among parents, students with disabilities, teachers, adult service providers, and employers are emphasized. Hanley-Maxwell, Pogoloff, and Whitney-Thomas
(1998) emphasized the role of families during transition periods. Families of young adults with disabilities played multiple roles, and these interacted and overlapped with each other. Only one literature was found that cited the participation of pediatricians in the transition process (Johnson, 1995).

Early and effective transition services increase the likelihood that a person with DD will complete school equipped with enough skills to move on to post secondary education and meaningful work (Gloekler, 1998). Chandler et al. (1996), Kluver et al. (1998), and McInerney and McInerney (1996) cited case study evidences of persons with DD who were able to find employment and were successfully living in the community. The cases described skills practice in natural environments, job related activities, assessment of work related capacities, and exposure to various jobs. Much of the report of transition outcomes described in literature used case study designs. Longitudinal studies exploring effects of programs from transition planning are scarce, if not nil.

\section{Method}

\section{Participants}

The target population for this study included parents of adolescents and adults with developmental disabilities. For inclusion in the study, the only criterion considered was for a parent or guardian to have a son or daughter, aged 14 and older, diagnosed with any one of the following: Autism/Autism Spectrum Disorder (ASD), Down syndrome and Cerebral palsy, Attention Deficit Disorder, and Mental retardation.

A list of their parent-members with children within the specified age group was obtained from the Autism Society of the Philippines, Down Syndrome Association, and the Philippine Cerebral Palsy, Inc. Assistance from two (2) pediatricians and one (1) occupational therapist was also sought in the distribution of questionnaires to patients/clients who fit the criterion. Anticipating difficulty in accessing the target population, sampling was not done. The 
study intended to include all parents/guardians who fit the inclusion criterion.

\section{Instrument}

A mail questionnaire was designed containing questions that addressed the research questions. Content was gathered from literature (Chandler et al., 1996; Getzel \& Kregel, 1996; Hanley-Maxwell, Whitney-Thomas et al., 1995; Johnson, 1995; McInerney \& McInerney, 1994; O'Reilly, 2000) and from interviews of 13 parents seen at the Clinic for Therapy Services, a campus based clinic. A developmental pediatrician, an occupational therapist, and survey design expert reviewed the questionnaire. The University of the Philippines Manila-Filipino Language Center translated the questionnaire to the Filipino language.

Both the English and Filipino versions of the questionnaire were pilot tested to 5 parents of children with special needs aged 14 and older. Revisions were done based on feedback of the parents and experts. Categories/items in the questionnaire were also coded to facilitate encoding and data analysis.

Each question contained choices for the respondents to select what was applicable to them (Fig. 1). The first part asked for demographic characteristics of respondents and their adolescent/ adult child with DD. Part II was for those respondents whose children were still enrolled in a school program. They responded to questions addressing current measures undertaken to prepare the person with DD from school to a post-school environment. Parents who reported having started transition were directed to proceed to questions in Part III that were relevant to them (questions four to eight). Part III was for those whose children were already in post-school environments. Questions pertained to the person's current activity level, residential status, transition activities undertaken, problems encountered (questions four and five), factors that facilitated or hindered the process (questions six and seven), and professionals (question eight) involved in transitioning.
Which of the following problems did your son/ daughter have during or after the transition period? (cross out all that apply)

* Confusion

* Depression

* Withdrawal from friends and family

* Anxiety

* Difficulty accommodating change

* Difficulty learning new routine

* Helplessness

* Increase in self-stimulatory behaviors

* Preference for inactivity

* Inadequate skills learned in school

* Lack of recreational/leisure options

* Difficulty making decisions

* Aggressive behavior

* No or lack of paid job options

* Frequent tardiness in present program

* Others, please specify

Fig. 1. Sample question

\section{Data collection and analysis}

A survey research method was employed for this study. Mailed questionnaires were coded with numbers for confidentiality to enable the investigator to track returns. Follow-up was conducted via telephone calls. Only those who had listed telephone numbers were contacted. Questionnaires were accompanied by a cover letter stating the purpose of the study, criteria for inclusion, and a statement of how their names were obtained. Postage paid business reply envelopes were included. A total of 344 questionnaires were sent out. Three hundred thirteen (313) were mailed. Thirty-one were distributed personally. Of those mailed, 19 were returned to sender with notations that addressees had moved with no forwarding addresses. Ninety-nine (99) were returned, yielding a response rate of $30 \%$. Response rate was calculated by dividing the number of surveys returned and completed $(n=99)$ by the population $(n=325)$. Of the 99 returned questionnaires, thirteen (13) were found to be unusable. If questionnaires come with missing pages, or if the children did not fit inclusion 
criterion, they were deemed unusable. The remaining 86 were used for data analysis.

Data analysis was done using descriptive statistics. Frequency counts and percentages and cross-tabulation were performed using the Statistical Package for the Social Sciences (SPSS) program.

\section{Results}

Although 86 questionnaires were used, some questions were not applicable to all and not all respondents completed questions applicable to them; therefore, the number of responses varied for some questions. There were also questions that asked respondents to cross out all options that apply. In such cases, the sum may be more than the $\mathrm{N}$ for some of the results presented below.

\section{Demographics}

Table 1 shows a demographic profile of the participants who were either parents or guardians of persons diagnosed with a developmental disability.

The mean age of the participants was 46 years. Clearly, over half of the group were middleaged adults $(76 \%)$ and female. Young adult participants $(14 \%)$ were sibling-guardians of persons with DD. There were slightly more respondents from Manila than from the provinces. A majority $(83 \%)$ received higher education. The group's $(\mathrm{n}=71)$ socio-economic profile reflected a middleclass to an upper middleclass background.

Mean age of adolescent/adult children with a developmental disability was 18 years. Their age range was $14-41$ years old. Over half (67\%) of the children were adolescents while the rest were young adults. Sixty-four (64) or 74 percent were males. A majority (48 or $56 \%$ ) was diagnosed with Autism. Others were diagnosed with Down syndrome (20 or $23 \%$ ), Cerebral palsy (12 or $14 \%$ ), Attention deficit disorder (3 or $1 \%$ ) and Mental retardation (3 or 1\%).

Fifty-three $(62 \%)$ of the children were still attending a school program. Thirty-three (38\%) were out of a school environment. Of those in school, more than half $(57 \%)$ were enrolled in special education programs. Programs attended
Table 1. Profile of parents/guardians

\begin{tabular}{|c|c|c|}
\hline Profile Characteristics & Frequency & Percentage $(\%)$ \\
\hline \multicolumn{3}{|l|}{ Age $(n=83)$} \\
\hline $20-30$ & 2 & 2 \\
\hline $31-40$ & 10 & 12 \\
\hline $41-50$ & 45 & 54 \\
\hline $51-60$ & 18 & 22 \\
\hline $61-70$ & 8 & 10 \\
\hline \multicolumn{3}{|l|}{$\operatorname{Sex}(n=85)$} \\
\hline Male & 18 & 21 \\
\hline Female & 67 & 79 \\
\hline \multicolumn{3}{|l|}{ Residence ( $\mathrm{n}=85$ ) } \\
\hline Manila & 45 & 53 \\
\hline Province & 40 & 47 \\
\hline \multicolumn{3}{|c|}{ Highest educ level $(n=82)$} \\
\hline Elementary & 5 & 6 \\
\hline High school & 9 & 11 \\
\hline College & 46 & 56 \\
\hline Graduate school & 22 & 27 \\
\hline \multicolumn{3}{|c|}{ Annual family income $(n=71)$} \\
\hline $39,999 \&$ under & 9 & 13 \\
\hline 40,000-99, 999 & 19 & 27 \\
\hline $100,000-499,999$ & 31 & 44 \\
\hline $500,000-$ over & 12 & 17 \\
\hline
\end{tabular}

were described as academic, vocational or both.

Among those in school $(n=53)$, over half $(62 \%)$ were perceived to extend their stay in a school environment up to adulthood. Of this group, less than half ( 22 or $42 \%$ ) were reported to be transitioning to a post-school environment. The rest (31 or $58 \%$ ) had not begun transition. Reasons for non-initiation of transition cited by a majority $(77 \%)$ included no awareness of need for transition, no knowledge of available services and professionals to consult with.

Among those who had left school environments ( $\mathrm{n}=33), 30$ (91\%) were home-based. One was working fulltime, another was enrolled in an adult education program, and one used to work in a computer shop but lost his job. Of this group, $25(76 \%)$ reported no measures were adopted to 
Table 2. Problems observed by parents/guardians

\begin{tabular}{lccc}
\hline Problems & $\begin{array}{c}\text { With Transition } \\
\mathrm{n}^{\mathrm{a}}(\%)\end{array}$ & $\begin{array}{c}\text { No transition } \\
\mathrm{n}^{\mathrm{b}}(\%)\end{array}$ & $\begin{array}{c}\text { Total } \\
\mathrm{n}(\%)\end{array}$ \\
\hline Psychological & $22(73)$ & $14(25)$ & $36(42)$ \\
Coping & $17(57)$ & $21(38)$ & $38(44)$ \\
Behavioral & $15(50)$ & $19(34)$ & $34(40)$ \\
Work & $23(77)$ & $14(25)$ & $37(43)$ \\
Environmental & $9(30)$ & $24(43)$ & $33(38)$ \\
\hline
\end{tabular}

$\mathrm{a}=30 ; \mathrm{b}=56$. Percentages add up to more than 100 due to multiple responses.

Table 3. Perceived factors affecting transition $(n=86)$

\begin{tabular}{lcc}
\hline Facilitating Factors & $\mathrm{n}$ & $\%$ \\
\hline Coordination among service providers & 76 & 88 \\
Early planning & 53 & 62 \\
Presence of support systems & 42 & 49 \\
Prior training/exposure to different & & \\
$\quad$ environments/activities & 38 & 44 \\
\hline Barriers & & \\
\hline Lack of services/programs & 79 & 92 \\
No planning & 74 & 86 \\
No knowledge of transition & 42 & 49 \\
Lack of support & 24 & 28 \\
Lack of coordination & 21 & 24 \\
Others (financial, stigma) & 13 & 15 \\
\hline
\end{tabular}

prepare their children for a post-school environment. Only $8(24 \%)$ reported conducting activities related to transition.

Altogether, 30 (35\%) underwent transition related activities and 56 (65\%) did not undergo any transition.

\section{Problems observed}

Problems reported observed during and after transition were classified into 5: psychological, coping, behavioral, work related and environmental (Table 2). Parents reported a mix of problems.

Table 2 shows that respondents of those with and without transition reported almost equally the same types of problems. A majority of the respondents, whose adolescent children underwent transition, observed more work, psychological, and coping related problems. In contrast, more environmental problems were observed among those without transition.

\section{Factors affecting transition}

Factors perceived to facilitate a smooth transition from school to a post-school environment included the following: early planning, coordination among service providers, presence of support systems (family and friends), and prior training in different environments/ activities (Table 3). In contrast, parents perceived the absence, or lack of such factors, to hinder smooth transition, that is, the absence or lack of planning, coordination among professionals, adolescent and adult programs, knowledge of transition, and support. Financial problems and stigma were also mentioned as barriers. 
Table 4. Transition activities $(n=30)$

\begin{tabular}{lcr}
\hline Transition Activities & $\begin{array}{c}\text { In school } \\
\mathrm{n}^{\mathrm{b}}(\%)\end{array}$ & $\begin{array}{c}\text { Not in School } \\
\mathrm{n}^{\mathrm{c}}(\%)\end{array}$ \\
\hline Planning with Professionals & $19(86)$ & $2(25)$ \\
Training in daily living skills & $12(55)$ & $7(88)$ \\
Counseling & $11(50)$ & $4(50)$ \\
Contact with GOs/NGOs ${ }^{\mathrm{a}}$ for job training & $10(45)$ & 0 \\
Contact with potential employer & $6(27)$ & 0 \\
Engagement in adult leisure activities & $1(5)$ & $2(25)$ \\
\hline
\end{tabular}

${ }^{a}$ government organizations/non-government organizations. ${ }^{b} n=22 .{ }^{c} n=8$.

\section{Transition activities}

Respondents described measures undertaken. Varied and multiple activities were employed as shown in Table 4. Those in school utilized a more varied and broader range of activities than those already out of school. Transition planning with relevant professionals was reported by a majority. Instruction in daily living skills was reported by all of those in an out of the school environment. Parents in this group did not contact government, non-government agencies, and potential employers during the transition period. Only two parents reported planning as part of transitioning.

\section{Professionals involved}

Of those whose children transitioned $(n=30)$, they identified educators $(46 \%)$ to be the predominant figures in transition. Thirty-seven percent reported the involvement of doctors. Occupational therapists and psychologists were mentioned by only $23 \%$ of the group. Thirteen percent involved family and friends. Potential employers $(3 \%)$ were hardly sought out in the transition process.

\section{Discussion}

This study elucidated that transition related dilemmas occur among persons with DD in the Philippines. It is a growing area of concern among families of this population. The profile of persons with DD in this study supported what is stated in literature that they are mostly unemployed. In the Philippine context, attention was drawn to one problem, which was the absence or lack of services and programs for adolescents/adults with DD. Some degree of transition activities was slowly emerging although most were parental initiatives. It was a multiple strategy process and collaboration among service providers. There was an interaction of factors that affected the outcome of such a process. There was an apparent need to educate families and professionals on the importance of transition preparedness and development of relevant programs for this population.

\section{Transition related problems}

The finding that occurrence of problems related to psychological, coping, work, and behavior areas of functioning was consistent with literature (Getzel \& Kregel, 1996; McInerney \& McInerney, 1994; Siporin, 1999). Work related problems such as poor attendance, difficulty acquiring new work skills, and mobility between the home and community environments suggested a lack of exposure to new environments and inadequate preparation for a post-school environment. This finding also matched with the report of Herge and Campbell (1999).

The presence of problems also showed that transition is not an easy phase for persons with DD (Chandler et al., 1996; Clark \& Kolstoe, 1995; Horne \& Morris, 1998; Johnson, 1995; McDonnell et al., 1991). Problems observed did not seem to emerge in isolation. The range of problems supported the idea that difficulties in one area were likely to affect others. Work related and coping problems were observed together with depression, and anxiety. Inability to effectively adjust in post- 
school environments suggested difficulty in transferring skills to daily living situations. This gave rise to depression, anxiety, and withdrawal from family and friends. According to Moloney, Whitney-Thomas, and Dreilinger (2000), these problems may be attributed to a lack of selfdefinition defined as having a sense of purpose, awareness of strengths and weaknesses, and ability to convey these to others. They suggested training to include interest exploration and decisionmaking to facilitate acquisition of self-definition.

Environmental problems least reported by those with transition, as compared to those without, implied that even if these problems existed, transition planning and activities minimized its negative effects. This was similarly reported by Chandler et al. (1996); Horne and Morris (1997); Hanley-Maxwell, WhitneyThomas et al. (1995).

The problems also suggested the lack of attention to the needs of adolescents and adults with DD (Getzel \& Kregel, 1996; Johnson, 1995). Johnson (1995) opined that the level of "transitionreadiness" affected outcome of transition programs (p.269). Considering that persons with DD achieve varying degrees of independence, timing of transition is crucial to success. Readiness to be transitioned to a post-school environment includes a critical decision that has to be made by parents and professionals involved. Measurement of outcomes related to transition varies according to set goals, levels of functioning, and cultural context. While many of the parents in this study expressed the need for transitioning for their adolescent and adult children, Filipino cultural values and beliefs influenced the final decisions in allowing their children to be more independent.

The report of these problems and the staggering number of those without transition indicated parents' uneasiness and concern for their children's future, which was similarly observed by Whitney-Thomas and Hanley-Maxwell (1996). Their uneasiness was made worse by the lack of knowledge and relevant services. Parents appeared to be communicating a quiet but desperate call for help to address employment and community adjustment requirements of their growing children.

\section{Factors affecting transition}

Parent perceptions of factors affecting transition showed a pattern of interaction among multiple factors. A relatively successful transition outcome could be predicted if most, if not all of the facilitating factors, were present (see Table 4). These factors corresponded to the essential elements of a transition program cited by Getzel and Kregel (1996); Hanley-Maxwell, WhitneyThomas et al. (1995); McInerney and McInerney (1994), and O'Reilly (2000). Johnson emphasized that transition for persons with developmental disabilities requires a deliberate planning process.

Because transitioning occurs within a context, its success largely depends on close collaboration among families, service providers, professionals, agencies, and potential employers. Chandler et al. (1996) described the process as a "shared responsibility" (p.55).

Access to support services and work training programs is important during transition. Experience in and exposure to work environments during this period was reported to be beneficial. The case of an adult child in this study, reported to adjust successfully, was akin to the cases cited by Chandler et al. (1996), Kluver et al. (1998), and McInerney and McInerney (1994).

In contrast, the absence of those factors perceived to facilitate smooth transition turned out to be barriers. The environmental related problems cited in a previous section included a factor in transition outcomes. The scarcity or absence of options such as work, leisure, and laws had impact on the success of transition among these persons. It seemed that inadequate implementation of the Magna Carta, pervading attitudes of Filipinos, economic, and political climates continue to serve as barriers to community integration of persons with disabilities. This is not to undermine the efforts in this positive direction. To a certain extent, the Philippine government - through the Magna Carta and its agencies such as the Department of Labor and Employment, National Council for the Welfare of Disabled Persons, and various nongovernment organizations-has projects that have 
had successful outcomes for persons with physical disabilities. However, it is still wanting for persons with DD. Major issues such as high unemployment, lack of educational and vocational opportunities, inaccessible workplaces, limited financial, and technical support continued to confront advocates of this movement ("Philippine disability scenario," 1995-1999). Perhaps, the Philippines have yet to learn from the experiences and models initiated in developed countries such as the United States, Canada, and Japan.

\section{Activities and involvement of professionals}

The scope of transition-related activities reportedly undertaken by parents and children included personal initiatives. Parents were the prime movers in the transition process. The initiative of parents to begin and be involved in the process played a significant role. Literature concurred with this finding (Hanley-Maxwell, Whitney-Thomas, \& Pogoloff, 1995; WhitneyThomas \& Hanley-Maxwell, 1996; Schuster, Graham, \& Moloney, 2000). Hanley Maxwell, Pogoloff, and Whitney-Thomas (1998) established the historic and emerging roles, and relationships of families during transition for young adults with disabilities. The network of family and friends, although not tapped by many, may be a valuable source of support and assistance in the transition process.

There was no clear and systematic protocol in activities undertaken by parents. A lack of clear guidelines, availability of, and access to transition programs was pervading. Results also suggested that there was a lack of vocational counselors, trainers, and job coaches in the Philippines. Transition is not only an issue of going through the process but also knowing how to go about it. This finding suggested that parents and service providers were unaware of the importance of transition. It has gained ground, however, in developed countries as reported by other professionals (Clark \& Kolstoe, 1995; Horne \& Morris, 1998; Johnson, 1995; McDonnell et al., 1991; Schlien \& Ray, 1997) and in OT literature (Ethridge et al., 1989; Getzel \& Kregel, 1996; Jacobs et al., 1985; McInerney \& McInerney, 1994; O’Reilly, 2000).
Findings of this study strongly validated that transition from school to post-school environments for young adults with DD is a turbulent time not only for them but for families as well. A shift from "child-centered" to "adultoriented" activities that characterized this period was not an easy feat (Johnson, 1995 p. 268).

Theoretical frames have long asserted that all individuals go through life span transitions (Blair, 2000). The average person is able to traverse transition periods by accepting and managing change using internal and external resources. However, persons with developmental disabilities face additional barriers to overcome transitions. Hence, they need additional resources and support to enable them to adjust to adult life demands and be integrated successfully into their communities.

\section{Study limitations}

Given that this study utilized a descriptive survey research, it is inevitable that it carries many of the inherent weaknesses of such a design. The length of the instrument, the interpretation of items, and use of mail in the collection of data may have affected response rate and interpretation of responses. Non-responses and low return rate may have affected validity and the potential for the findings of this study to be generalized to the relevant population. Also, the study did not utilize statistical tests to determine significant differences between groups.

\section{Conclusions}

The dilemmas and status of transition-related activities reported in this study supported the view that the growing population of Filipino adolescents and adults with DD are underserved. Programs and services such as work training, job placement, transportation, group residences were clearly deficient, if not absent. Another significant concern is the lack of knowledge on the importance of transition.

It is imperative for occupational therapy, education practitioners, and other health professionals in the Philippines to work together in exploring and developing programs for adolescents and adults with developmental 
disabilities. For Filipino occupational therapy practitioners, efforts must be exerted to shift from a modality-specific to an occupation-based practice. The lack of advocacy work toward community inclusion among government, private entities and employers remain a continuing concern. Longitudinal studies are needed to explore the nature and efficacy of transition programs in helping these persons respond appropriately to adult life demands. Understanding the process of transition in the context of Filipino and Asian culture is another research direction.

Acknowledgements: I thank the parents and guardians who participated in the pilot test and actual conduct of this study; the officers and staff of the Autism Society of the Philippines, Down Syndrome Association of the Philippines, and the Philippine Cerebral Palsy, Inc.; Clinic for Therapy Services; Learning Partners, Inc; Dean Susan B. Villegas, Prof. Maridel Borja; Drs. Alexis Reyes and Ria de Guzman, Ms. Josephine Nepomuceno, Mr. Rolland Lyle Duque, Ms. Hazel Pascua, Mr. Butch Regala, Ms. Yolanda Capaque, Ms. Rizalina Cruz, Ms. Fe Cagata, Ms. Mariel Apejas, Mr. Benjamin Malihan for their support and assistance.

This study was supported by the Charlotte A. Floro Professorial Chair.

A portion of this study was presented in poster format at the 13th World Congress of Occupational Therapists in Stockholm, Sweden in June 23-28, 2002.

\section{References}

Blair, S.E. (2000). The centrality of occupation during life transitions. British J. Occup. Ther. 63(5), 231-237.

Chandler, J., O'Brien, P., \& Weinstein, L. (1996). The role of occupational therapy in the transition from school to work for adolescents with disabilities. Work: A Journal of Prevention, Assessment and Rehabilitation,. 6, 53-59.

Clark, G.M., \& Kolstoe, O.P. (1995). Career development \& transition education for adolescents with disabilities (2nd ed). Boston: Allyn and Bacon.
Davidson, D.A., \& Fitzgerald, L. (2001). Transition planning for students. OT Practice, 6(17), 17-20.

Ethridge, D.A., Dimmer, P., Harrison, B., \& Davis, D. (1989). Occupational therapy in a regional comprehensive service system. Occup. Ther. in Health Care, 6, 91-106.

Getzel, E., \& Kregel, J. (1996). Transitioning from the academic to the employment setting: The employment connection program. J. Vocational Rehabil. 6, 273-287.

Giese, T. (June 2000). Occupational therapy opportunities in the transition to independent living. OT Practice, 5(12), 15-19.

Gloekler, L. (March 1998). A state's director's perspective on transition and the IDEA reauthorization. Liaison Bulletin, 28(4). Retrieved September 15, 2000, from http://www.nasdse.org/ home.htm.

Hanley-Maxwell, C., Whitney-Thomas, J., \& Pogoloff, S. (1995). The second shock: A qualitative study of parents' perspectives and needs during their child's transition from school to adult life. The Journal of the Association for Persons with Severe Handicaps, 20, 3-15.

Hanley-Maxwell, C., Pogoloff, S.M., \& WhitneyThomas, J. (1998). Families in the heart of Transition. In F.R. Rusch, \& J. Chadsey-Rusch, (Eds.), Beyond high school: Transition from school to work. pp. 234-264. Belmont, California: Wadsworth Publishing.

Herge, E.A., \& Campbell, J.E. (1999). Older adults with mental retardation/developmental delay challenges and opportunities. OT Practice, 4(5), 16-21.

Horne, R.L., \& Morris, S. (March 1998). Transition of youth with disabilities. Liaison Bulletin, 28(4). Retrieved September 15, 2000 from http:// www.nasdse.org/home.htm.

Jacobs, K., Mazonson, N., Pepicelli, K., Clague, I., \& Leekoff, W. (1985). A work center: A schoolbased program for vocational preparation of special needs children and adolescents. Occup. Ther. in Health Care, 2(4), 47-57.

Johnson, C.P. (May 1995). Transition into adulthood. J. Continuing Pediatric Education, 24(5), 268273.

Kluver, J., Clark, M., \& Hoffman, B. (September 1998). A community program for adults with developmental disabilities. OT Practice, 3(8), 3136.

McDonnell, J., Wilcox, B., \& Hardman, M. (1991). Secondary programs for students with 
developmental disabilities. Boston: Allyn and Bacon.

McInerney, C.A., \& McInerney, M. (1994). Occupational therapy and school to work transition: A preventive education model. Occup. Ther. International, 1, 158-173.

Moloney, M., Whitney-Thomas, J., \& Dreilinger, D. (2000). Self-determination and struggle in the lives of adolescents. Research to Practice, 6(2), 1-4. Boston: Institute for Community Inclusion.

O'Reilly, A. (October 2000). Transition services planning and the school based therapist. $O T$ Practice, 5(20), 14-17.

Philippine disability scenario: Employment (19951999). In policy issues and recommendations for the sector of persons with disabilities in the Philippines. Breaking barriers-a Philippine project. pp. 19-26. Manila: Katipunan ng mga May Kapansanan sa Pilipinas, Inc.(KAMPI) and the Danish Society of Polio and Accident Victims.

Reyes, A.L. (1990). Developmental disorders A practical approach. Journal of Pediatrics,
Obstetrics and Gynecology, (Supplement), 15-19. Rice, F.P. (1995). Human development-A life span approach. 2nd ed. New Jersey: Prentice Hall.

Schlien, S.J., \& Ray, M.T. (1997). Leisure Education for a Quality Transition to Adulthood. Journal of Vocational Rehabilitation, 8(2), 155-169.

Schulz,R., \& Ewen, R. (1993). Adult development and aging-Myths and emerging-realities (2nd ed). New York: MacMillan Publishing Co.

Schuster, J., Graham, S., \& Moloney, M. (2000). Building a future: Working with the post-high school expectations of students and parents. Research to Practice, 6(1), 1-3. Boston: Institute for Community Inclusion.

Siporin, S. (1999). Help wanted supporting workers with developmental disabilities. OT Practice, 4(8), 19-24.

Whitney-Thomas, J., \& Hanley-Maxwell, C. (1996). Packing the parachute: Parents' experiences as their children prepare to leave high school. Exceptional Children, 63(1), 75-87. 